\title{
Características químicas de solo sob aplicação de esterco líquido de suínos em pastagem natural(1)
}

\author{
Carlos Alberto Ceretta(2), Reges Durigon ${ }^{(3)}$, Claudir José Basso ${ }^{(3)}$, Luiz Antônio Rocha Barcellos ${ }^{(4)}$ \\ e Frederico Costa Beber Vieira(5)
}

\begin{abstract}
Resumo - Apesar de o esterco líquido de suínos ser um fertilizante, seu uso inadequado pode comprometer a qualidade do solo e água. O objetivo deste trabalho foi avaliar alterações em algumas características químicas de um solo sob pastagem natural com o uso de esterco líquido de suínos e suas implicações agronômicas e ambientais. O experimento foi conduzido de novembro de 1995 a novembro de 1999 em Paraíso do Sul, RS, em condomínio de suinocultores. Os tratamentos constituíram-se de 0, 20 e $40 \mathrm{~m}^{3} \mathrm{ha}^{-1}$ de esterco líquido de suínos, aplicado em intervalos de 45 a 60 dias. Em cada época de aplicação de esterco, a pastagem natural era roçada, a forragem retirada e o esterco reaplicado. Os resultados mostraram que o uso sistemático de esterco líquido de suínos representa a adição de grandes quantidades de nutrientes ao solo, elevando principalmente os teores de $\mathrm{P}, \mathrm{Ca}$ e $\mathrm{Mg}$ em áreas sob pastagem natural. $\mathrm{O}$ ambiente para o crescimento das plantas também pode ser melhorado com o uso de esterco líquido de suínos pela diminuição na saturação de $\mathrm{Al}$, mas deve-se monitorar o teor de $\mathrm{K}$ no solo, porque, sob pastoreio, os teores podem decrescer. $\mathrm{O}$ fato de adicionar altas quantidades de $\mathrm{N}$ por meio do esterco líquido de suínos sem alterar seus teores no solo evidencia que ocorrem grandes perdas de N, principalmente na forma de nitrato. Além disso, a elevada concentração de P na camada mais superficial do solo mostra que estes elementos podem comprometer a qualidade do ambiente, especialmente como contaminantes da água.
\end{abstract}

Termos para indexação: água, contaminação ambiental, disponibilidade de nutriente, manejo de resíduos.

\section{Soil chemical characteristics of native pasture affected by liquid swine manure}

Abstract - Pig slurry is a fertilizer but its improper use can contaminate water and soil. The objectives of this study were to determine soil chemical attributes affected by liquid swine manure applied on native pasture and to evaluate the agronomic and environmental impacts of its use. An experiment with liquid swine manure application on native pasture was carried out from November 1995 to November 1999, in an area nearby a swine production place in Paraíso do Sul county, State of Rio Grande do Sul, Brazil, to evaluate the soil chemical attributes. The liquid swine manure application rates were: 0,20 and $40 \mathrm{~m}^{3} \mathrm{ha}^{-1}$, applied every 45 to 60 days. Right before each manure application, the forage was mowed and taken out. The liquid manure application on natural grass field every 45 to 60 days cause a high addition of soil chemical elements, specially $\mathrm{P}, \mathrm{Ca}$ and $\mathrm{Mg}$. The reduction of Al saturation may improve soil environment to plant growth, however, the K content should be monitored, because under grazing the latter could decrease. The system should have high $\mathrm{N}$ leaching in nitrate form, because, despite heavy $\mathrm{N}$ application through manure, the soil $\mathrm{N}$ content remains almost the same. This, in turn, could become an environmental problem, as long as one consider a high $\mathrm{P}$ content at surface also as potential water pollutant.

Index terms: water, environmental contamination, nutrients availability, waste management.

(1)Aceito para publicação em 12 de março de 2003.

Extraído da dissertação de mestrado apresentada pelo segundo autor à Universidade Federal de Santa Maria (UFSM), Santa Maria, RS. Trabalho parcialmente financiado pela Fapergs, Pronex e CNPq.

(2) UFSM, Dep. de Solos, Faixa Camobi, km 9, CEP 97105-900 Santa Maria, RS. Bolsista do CNPq. E-mail: ceretta@ccr.ufsm.br
(3)UFSM, Dep. de Solos. E-mail: rdurigon@bol.com.br, cjbasso@bol.com.br

(4) Empresa de Assistência Técnica e Extensão Rural, Av. Medianeira, 278, CEP 97060-000 Santa Maria, RS. E-mail: larbarcellos@emater.tche.br

(5) Universidade Federal do Rio Grande do Sul, Dep. de Solos, Caixa Postal 776, CEP 90001-970 Porto Alegre, RS. E-mail: fredericocbv@yahoo.com.br 


\section{Introdução}

Os solos com pastagem natural no Rio Grande do Sul são na sua maioria ácidos, com baixa disponibilidade de nutrientes e altos teores de $\mathrm{Al}$ em solução. $\mathrm{O}$ uso de esterco líquido de suínos pode melhorar estas condições pelo seu potencial fertilizante. Entretanto, seu uso deve ser criterioso, pois o esterco representa um potencial poluente para o ambiente, e pode comprometer a qualidade do solo e água.

$\mathrm{O} \mathrm{N}$ é um dos principais constituintes do esterco líquido de suínos. Cerca de $50 \%$ desse $\mathrm{N}$ está na forma mineral (Barcellos, 1992), e ao ser aplicado tem efeito imediato no crescimento das plantas. Por sua vez, o escoamento superficial e a lixiviação no solo podem contaminar mananciais de água com nitrato. $\mathrm{O} \mathrm{K}$ se encontra no esterco totalmente na forma mineral, solúvel e, por isso, seu efeito residual é muito curto. Plantas com alta taxa de absorção de K diminuem suas perdas potenciais no sistema.

Aproximadamente dois terços do $\mathrm{P}$ presente no esterco líquido de suínos está numa forma não solúvel em água, fazendo parte de estruturas orgânicas (Barcellos, 1992), as quais propiciam efeito residual ao esterco. Aplicações sucessivas de esterco podem causar acúmulo de $\mathrm{P}$ no solo, conforme observou Pratt (1979). Sua maior presença na camada superficial do solo é indesejável, pois favorece as perdas por escoamento superficial que, junto com o $\mathrm{P}$ que se movimenta no perfil do solo, podem causar eutroficação da água, conforme Giusquiani et al. (1998). Tal fato ficou demonstrado por Hountin et al. (2000), que verificaram incrementos de 16, 26, 33 e $50 \%$ em todas as formas de $\mathrm{P}$ até a profundidade de $1 \mathrm{~m}$ após aplicação de 30, 60, 90 e $120 \mathrm{~m}^{3} \mathrm{ha}^{-1}$ de esterco líquido de suínos, respectivamente.

A possibilidade de alteração no $\mathrm{pH}$ do solo com a aplicação de esterco líquido de suínos é mínima, principalmente tratando-se de solos altamente tamponados (Scherer et al., 1984), ainda que os teo- res de alumínio possam ser diminuídos, especialmente pelo incremento de compostos orgânicos de baixo peso molecular.

O objetivo deste trabalho foi avaliar alterações em algumas características químicas de um solo sob pastagem natural com o uso de esterco líquido de suínos e suas implicações agronômicas e ambientais.

\section{Material e Métodos}

O experimento iniciou-se em novembro de 1995 e os resultados apresentados referem-se ao período até novembro de 1999. A área experimental pertence a um condomínio suinícola situado no Município de Paraíso do Sul, na região fisiográfica da Depressão Central do Rio Grande do Sul. O solo é classificado como Alissolo Crômico Órtico típico (Embrapa, 1999) e pertence à unidade de mapeamento Santa Maria. Os resultados da análise química do solo nas camadas $0-10 \mathrm{~cm}$ e $10-20 \mathrm{~cm}$ de profundidade são mostrados na Tabela 1 .

Os tratamentos constituíram-se de 0,20 e $40 \mathrm{~m}^{3} \mathrm{ha}^{-1}$ de esterco líquido de suínos, aplicado em intervalos de 45 a 60 dias, o que corresponderia ao intervalo de tempo no qual os tanques de armazenamento (esterqueiras) estariam cheios novamente e o produtor deveria dar um destino ao esterco. O delineamento experimental utilizado foi de blocos casualizados com quatro repetições. As unidades experimentais constituíram-se de parcelas de 4,0x3,5 m.

As aplicações do esterco líquido de suínos foram realizadas manualmente e em superfície, logo após cada coleta de amostras da matéria vegetal aérea e corte e retirada total da vegetação da área experimental. No momento de cada aplicação, foi analisada a densidade do esterco para determinação da matéria seca, utilizando-se densímetro e proveta. Os teores de $\mathrm{N}, \mathrm{P}, \mathrm{K}, \mathrm{Ca}$ e $\mathrm{Mg}$ totais no esterco líquido de suínos foram determinados conforme métodos descritos em Tedesco et al. (1995).

Durante o período experimental, foram realizadas 28 aplicações de esterco líquido de suínos. A concentração média e a quantidade total de nutrientes aplicados em cada dose encontram-se na Tabela 2.

A amostragem do solo foi realizada anualmente $\left(5 / 8 / 96,1^{\circ} / 7 / 97,30 / 6 / 98\right.$ e 6/11/99) nas profundidades de

Tabela 1. Características do solo sob pastagem natural em duas profundidades.

\begin{tabular}{|c|c|c|c|c|c|c|c|c|c|c|c|c|c|}
\hline \multirow{2}{*}{$\begin{array}{l}\text { Profundidade } \\
(\mathrm{cm})\end{array}$} & \multirow{2}{*}{$\begin{array}{c}\text { Argila } \\
\left(\mathrm{g} \mathrm{kg}^{-1}\right)\end{array}$} & \multirow{2}{*}{$\begin{array}{c}\mathrm{pH}-\mathrm{H}_{2} \mathrm{O} \\
(1: 1) \\
\end{array}$} & \multirow{2}{*}{$\begin{array}{l}\text { Índice } \\
\text { SMP }\end{array}$} & \multirow{2}{*}{$\begin{array}{cc}\mathrm{P} & \mathrm{K}^{+} \\
---\left(\mathrm{mg} \mathrm{dm}^{-3}\right)--- \\
\end{array}$} & \multirow{2}{*}{$\begin{array}{c}\mathrm{MO} \\
\left(\mathrm{g} \mathrm{kg}^{-1}\right)\end{array}$} & \multirow{2}{*}{\multicolumn{2}{|c|}{$\begin{array}{l}\mathrm{Al}^{3+} \mathrm{Ca}^{2+} \\
---\left(\mathrm{cmol}_{\mathrm{c}} \mathrm{dm}^{-}\right.\end{array}$}} & \multirow{2}{*}{$\begin{array}{l}\mathrm{Mg}^{2+} \\
-3)----\end{array}$} & \multirow{2}{*}{$\begin{array}{c}\mathrm{H}+\mathrm{Al} \\
\left(\mathrm{cmol}_{\mathrm{c}} \mathrm{dm}^{-3}\right)\end{array}$} & \multicolumn{2}{|c|}{ CTC $\left(\mathrm{cmol}_{\mathrm{c}} \mathrm{dm}^{-3}\right)$} & \multicolumn{2}{|c|}{ Saturação (\%) } \\
\hline & & & & & & & & & & Efetiva & $\mathrm{pH} \mathrm{7,0}$ & $\mathrm{Al}^{3+}$ & Bases \\
\hline & & & 4 & 190 & 35 & 4.1 & 38 & 1 , & & 9 , & 17 & & 33 \\
\hline $10-20$ & 160 & 5,1 & 4,7 & 192 & 28 & 4,0 & 3,8 & 1,4 & 11,5 & 9,7 & 17,0 & 41 & 33 \\
\hline
\end{tabular}


0-2,5, 2,5-5,0, 5,0-10, 10-20 e 20-40 cm, utilizando-se trado calador, e as análises foram realizadas segundo métodos descritos em Tedesco et al. (1995). Foi analisado o carbono orgânico por meio de oxidação por $\mathrm{K}_{2} \mathrm{Cr}_{2} \mathrm{O}_{7}+\mathrm{H}_{2} \mathrm{SO}_{4}$, segundo o método de Walkley-Black (Allison, 1965); $\mathrm{N}$ total pelo método de Kjeldahl (oxidação úmida); $\mathrm{P}$ e K disponíveis pelo extrator Mehlich-1; $\mathrm{Ca}$, $\mathrm{Mg}$ e $\mathrm{Al}$ trocáveis extraídos com sal neutro $\left(\mathrm{KCl} 1 \mathrm{~mol} \mathrm{dm}^{-3}\right)$ e pH em água.

Os resultados foram submetidos à análise de variância, sendo as variáveis analisadas como bifatorial (profundidade de amostragem $\mathrm{x}$ doses de esterco) e as médias comparadas pelo teste de Duncan a 5\% de probabilidade de erro.

\section{Resultados e Discussão}

As características químicas do solo foram afetadas pelo uso de esterco líquido de suínos durante quatro anos, havendo interação entre as doses e profundidade do solo (Tabela 3). $\mathrm{O}$ incremento nos teores de $\mathrm{C}$ orgânico e $\mathrm{N}$ total ocorreu apenas na camada $0-2,5 \mathrm{~cm}$, embora na sua interpretação deva-se considerar a possibilidade de efeito da amostragem do solo, já que resíduos vegetais ou do esterco misturam-se com o solo nesta camada até $2,5 \mathrm{~cm}$, dificultando sua separação.

O fato de a aplicação de esterco não resultar em incrementos nos teores de $\mathrm{C}$ orgânico e $\mathrm{N}$ total nas camadas mais profundas deve-se, provavelmente, ao aumento na atividade microbiana motivada pelo esterco aplicado (N'Dayegamiye \& Côté, 1989). Além do baixo teor de matéria seca que caracterizou o esterco utilizado, os compostos orgânicos presentes são de fácil mineralização, oxidando em poucos dias ou semanas (Redoy et al., 1979). Além disso, os resíduos da vegetação eram retirados da área experimen- tal, diminuindo o aporte de material orgânico ao solo.

O fator que mais influencia a persistência da matéria orgânica no solo é a sua própria proteção física, originada pela interação com argilominerais e óxidos de Fe e Al (Ceretta, 1995). Em solo com pastagem natural e com baixo teor de argila, como o do presente trabalho, em que o teor de argila é de apenas $150 \mathrm{~g} \mathrm{~kg}^{-1}$, a proteção física da matéria orgânica é pequena, favorecendo a sua decomposição, e proporcionando um estado estacionário da matéria orgânica no tempo, com quantidades adicionadas e perdidas equivalentes (Bayer \& Mielniczuk, 1999). A introdução de espécies forrageiras com maior potencial de produção de matéria seca poderia não alterar o teor de matéria orgânica no solo mas contribuiria para melhorar a ciclagem dos nutrientes do esterco.

As quantidades de $\mathrm{N}$ adicionadas ao solo foram altas $\mathrm{e}$ inferiores apenas às de $\mathrm{P}$ (Tabela 2). Entretanto, neste mesmo experimento, Durigon et al. (2002) mostraram que apenas $53 \%$ e $35 \%$ do $\mathrm{N}$ aplicado por meio do esterco líquido de suínos nas doses de 20 e $40 \mathrm{~m}^{3} \mathrm{ha}^{-1}$, respectivamente, foram exportados pela matéria seca da pastagem natural. Logo, as perdas de $\mathrm{N}$ aplicado por meio do esterco foram expressivas, e podem ter ocorrido por volatilização de amônia, escoamento superficial ou lixiviação na forma de nitrato. Apesar dos porcentuais de perdas de $\mathrm{N}$ por volatilização de amônia atingirem valores de $45 \%$ a $63 \%$ do $\mathrm{N}$ amoniacal (Moal et al., 1995), o principal problema ambiental relacionado ao uso do esterco como fertilizante é a lixiviação de $\mathrm{N}$ na forma de nitrato (Gangbazo et al., 1995), especialmente no caso em que o esterco apresentava um teor médio de $3,23 \mathrm{~kg} \mathrm{~m}^{-3} \mathrm{de} \mathrm{N}$, considerado alto.

Tabela 2. Concentração média e quantidade total de nutrientes e carbono aplicados em pastagem natural mediante doses de esterco líquido de suínos durante quatro anos ${ }^{(1)}$.

\begin{tabular}{ccccccc}
\hline Esterco $\left(\mathrm{m}^{3} \mathrm{ha}^{-1}\right)$ & $\mathrm{N}$ & $\mathrm{P}$ & \multicolumn{1}{c}{$\mathrm{K}^{+}$} & $\mathrm{Ca}^{2+}$ & $\mathrm{Mg}^{2+}$ & $\mathrm{C}$ \\
\hline & & \multicolumn{5}{c}{ Concentração média $\left(\mathrm{kg} \mathrm{m}^{-3}\right)$} \\
& 3,23 & 3,64 & 2,64 & 1,00 & 0,96 & 15,0 \\
\cline { 2 - 7 } & & \multicolumn{6}{c}{ Quantidade total $\left(\mathrm{Mg} \mathrm{ha}^{-1}\right)$} \\
40 & 1,81 & 2,04 & 1,48 & 0,56 & 0,54 & 8,4 \\
\hline
\end{tabular}

${ }^{(1)}$ Média das 28 amostras de esterco líquido de suínos, nas quais o teor de matéria seca médio foi de 5\%. 
Tabela 3. Teor de $\mathrm{C}$ orgânico, $\mathrm{N}$ total, $\mathrm{P}, \mathrm{K}, \mathrm{Ca}, \mathrm{Mg}, \mathrm{Al}$ e $\mathrm{pH}$ em diferentes profundidades de solo com pastagem natural após quatro anos de aplicação de esterco líquido de $\operatorname{suínos}^{(1)}$.

\begin{tabular}{|c|c|c|c|}
\hline \multirow[t]{2}{*}{ Profundidade $(\mathrm{cm})$} & \multicolumn{3}{|c|}{ Doses de esterco líquido de suínos $\left(\mathrm{m}^{3} \mathrm{ha}^{-1}\right)$} \\
\hline & 0 & 20 & 40 \\
\hline & \multicolumn{3}{|c|}{ C orgânico $\left(\mathrm{g} \mathrm{kg}^{-1}\right)$} \\
\hline $0-2,5$ & $37,3 \mathrm{Ba}$ & $41,1 \mathrm{Aa}$ & $42,2 \mathrm{Aa}$ \\
\hline $2,5-5,0$ & $23,8 \mathrm{Ab}$ & $23,5 \mathrm{Ab}$ & $22,3 \mathrm{Ab}$ \\
\hline $5-10$ & $18,0 \mathrm{Ac}$ & $16,4 \mathrm{Ac}$ & $19,3 \mathrm{Ac}$ \\
\hline $10-20$ & $17,2 \mathrm{Ac}$ & $16,2 \mathrm{Ac}$ & $15,9 \mathrm{Ad}$ \\
\hline $20-40$ & $10,4 \mathrm{Ad}$ & $12,1 \mathrm{Ad}$ & $10,3 \mathrm{Ae}$ \\
\hline & \multicolumn{3}{|c|}{$\mathrm{N}$ total $\left(\mathrm{g} \mathrm{kg}^{-1}\right)$} \\
\hline $0-2,5$ & $5,59 \mathrm{Ba}$ & $6,21 \mathrm{Aa}$ & $6,23 \mathrm{Aa}$ \\
\hline $2,5-5,0$ & $3,43 \mathrm{Ab}$ & $3,41 \mathrm{Ab}$ & $3,22 \mathrm{Ab}$ \\
\hline $5-10$ & $2,42 \mathrm{Ac}$ & $2,36 \mathrm{Ac}$ & $2,40 \mathrm{Ac}$ \\
\hline $10-20$ & $2,28 \mathrm{Ac}$ & $2,18 \mathrm{Ac}$ & $2,18 \mathrm{Ad}$ \\
\hline $20-40$ & $1,42 \mathrm{Ad}$ & $1,50 \mathrm{Ad}$ & $1,52 \mathrm{Ae}$ \\
\hline & \multicolumn{3}{|c|}{$\mathrm{P}$ disponível $\left(\mathrm{mg} \mathrm{dm}^{-3}\right)$} \\
\hline $0-2,5$ & $25,3 \mathrm{Ca}$ & $1.203 \mathrm{Ba}$ & $1.664 \mathrm{Aa}$ \\
\hline $2,5-5,0$ & $14,1 \mathrm{Cb}$ & $669 \mathrm{Bb}$ & $1.103 \mathrm{Ab}$ \\
\hline $5-10$ & $8,3 \mathrm{Cc}$ & $214 \mathrm{Bc}$ & $551 \mathrm{Ac}$ \\
\hline $10-20$ & $5,7 \mathrm{Ccd}$ & $55 \mathrm{Bd}$ & $103 \mathrm{Ad}$ \\
\hline $20-40$ & $1,8 \mathrm{Cd}$ & $12 \mathrm{Bd}$ & $29 \mathrm{Ae}$ \\
\hline & \multicolumn{3}{|c|}{$\mathrm{K}$ disponível $\left(\mathrm{mg} \mathrm{dm}^{-3}\right)$} \\
\hline $0-2,5$ & $177 \mathrm{Aa}$ & $93 \mathrm{Ba}$ & $119 \mathrm{Ba}$ \\
\hline $2,5-5,0$ & $119 \mathrm{Ab}$ & $52 \mathrm{Bb}$ & $71 \mathrm{Bb}$ \\
\hline $5-10$ & $85 \mathrm{Ac}$ & $43 \mathrm{Bb}$ & $48 \mathrm{Bb}$ \\
\hline $10-20$ & 72Ac & $40 \mathrm{Bb}$ & $40 \mathrm{Bb}$ \\
\hline $20-40$ & $68 \mathrm{Ac}$ & $51 \mathrm{Ab}$ & $49 \mathrm{Ab}$ \\
\hline & \multicolumn{3}{|c|}{ Ca trocável $\left(\mathrm{cmol}_{\mathrm{c}} \mathrm{dm}^{-3}\right)$} \\
\hline $0-2,5$ & $4,70 \mathrm{Ba}$ & $7,04 \mathrm{Aa}$ & $6,99 \mathrm{Aa}$ \\
\hline $2,5-5,0$ & $2,99 \mathrm{Bb}$ & $4,07 \mathrm{Ab}$ & $4,18 \mathrm{Ab}$ \\
\hline $5-10$ & $2,70 \mathrm{Ab}$ & $3,09 \mathrm{Ac}$ & $3,23 \mathrm{Abc}$ \\
\hline $10-20$ & $2,38 \mathrm{Abc}$ & $2,81 \mathrm{Ac}$ & 2,60 Acd \\
\hline $20-40$ & $1,59 \mathrm{Ac}$ & $1,79 \mathrm{Ad}$ & $2,08 \mathrm{Ad}$ \\
\hline & \multicolumn{3}{|c|}{$\mathrm{Mg}$ trocável $\left(\mathrm{cmol}_{\mathrm{c}} \mathrm{dm}^{-3}\right)$} \\
\hline $0-2,5$ & $1,93 \mathrm{Ba}$ & 4,49Aa & $4,58 \mathrm{Aa}$ \\
\hline $2,5-5,0$ & $0,96 \mathrm{Cb}$ & $2,55 \mathrm{Bb}$ & $3,54 \mathrm{Ab}$ \\
\hline $5-10$ & $0,59 \mathrm{Cbc}$ & $1,28 \mathrm{Bc}$ & $2,50 \mathrm{Ac}$ \\
\hline $10-20$ & $0,42 \mathrm{Bc}$ & $0,67 \mathrm{Bd}$ & $1,29 \mathrm{Ad}$ \\
\hline $20-40$ & $0,33 \mathrm{Ac}$ & $0,38 \mathrm{Ad}$ & $0,54 \mathrm{Ae}$ \\
\hline \multicolumn{4}{|c|}{ Al trocável $\left(\mathrm{cmol}_{\mathrm{c}} \mathrm{dm}^{-3}\right)$} \\
\hline $0-2,5$ & $1,41 \mathrm{Aa}$ & $0,14 \mathrm{Bd}$ & $0,26 \mathrm{Be}$ \\
\hline $2,5-5,0$ & $3,60 \mathrm{Ac}$ & $1,51 \mathrm{Bc}$ & $0,88 \mathrm{Cd}$ \\
\hline $5-10$ & $4,05 \mathrm{Abc}$ & $3,29 \mathrm{Bb}$ & $2,01 \mathrm{Cc}$ \\
\hline $10-20$ & $4,49 \mathrm{Ab}$ & $3,72 \mathrm{Bb}$ & $3,36 \mathrm{Bb}$ \\
\hline $20-40$ & 7,14Aa & $6,94 \mathrm{Aa}$ & $6,28 \mathrm{Aa}$ \\
\hline \multicolumn{4}{|c|}{$\mathrm{pH}-\mathrm{H}_{2} \mathrm{O}$} \\
\hline $0-2,5$ & $5,1 \mathrm{Ba}$ & $5,2 \mathrm{Aa}$ & $5,2 \mathrm{Aa}$ \\
\hline $2,5-5,0$ & $5,0 \mathrm{Ba}$ & $5,1 \mathrm{Ab}$ & $5,2 \mathrm{Aa}$ \\
\hline $5-10$ & $5,1 \mathrm{Ba}$ & $5,1 \mathrm{Ab}$ & $5,2 \mathrm{Aa}$ \\
\hline $10-20$ & $5,1 \mathrm{Aa}$ & $5,2 \mathrm{Aa}$ & $5,1 \mathrm{Aa}$ \\
\hline $20-40$ & $5,1 \mathrm{Aa}$ & $5,2 \mathrm{Aa}$ & $5,0 \mathrm{Bb}$ \\
\hline
\end{tabular}

${ }^{(1)}$ Médias seguidas pela mesma letra, maiúscula na linha e minúscula na coluna, não diferem pelo teste de Duncan a $5 \%$ de probabilidade de erro. 
O teor de $\mathrm{P}$ disponível no solo aumentou consideravelmente com a aplicação do esterco ao longo do tempo (Figura 1). Aos 8,3 meses de aplicação de esterco, o aumento na quantidade de $\mathrm{P}$ disponível na camada $0-10 \mathrm{~cm}$ foi de $242 \%$ e $580 \%$ com aplicação de 20 e $40 \mathrm{~m}^{3} \mathrm{ha}^{-1}$, respectivamente; aos 48 meses, o incremento foi de $3.943 \%$ e $6.710 \%$ com as doses de 20 e $40 \mathrm{~m}^{3} \mathrm{ha}^{-1}$, respectivamente, atingindo teores extremamente altos de $\mathrm{P}$ disponível no solo, uma vez que, para esta condição de solo, teores de $\mathrm{P}$ acima de $24 \mathrm{mg} \mathrm{dm}^{-3}$ são considerados altos (Comissão de Fertilidade do Solo - RS/SC, 1995).

Esses resultados evidenciam que se deve atentar para o potencial poluente do $\mathrm{P}$ no ambiente, evitando-se a aplicação de altas doses de esterco em pequenas áreas, e adotando-se medidas técnicas que permitam maior taxa de infiltração da água no solo, e sistemas de culturas que proporcionem a produção e manutenção de altas quantidades de resíduos vegetais sobre a superfície do solo, a fim de diminuir o escoamento superficial. Embora em alguns casos as perdas de $\mathrm{P}$ sejam pequenas, mesmo concentrações relativamente baixas $\left(0,01 \mathrm{mg} \mathrm{dm}^{-3}\right.$ de P solúvel ou $0,02 \mathrm{mg} \mathrm{dm}^{-3}$ de P total) são suficientes para causar eutroficação (Sharpley \& Rekolainen, 1997).

Houve migração de $\mathrm{P}$ às camadas mais profundas do solo, com o uso de maior dose de esterco (Tabela 3). Se de 20 para $40 \mathrm{~m}^{3} \mathrm{ha}^{-1}$ significou o dobro de esterco aplicado, o teor de P no solo aumentou 2,57 e 2,41 vezes nas camadas $5-10 \mathrm{~cm}$ e $20-40 \mathrm{~cm}$,

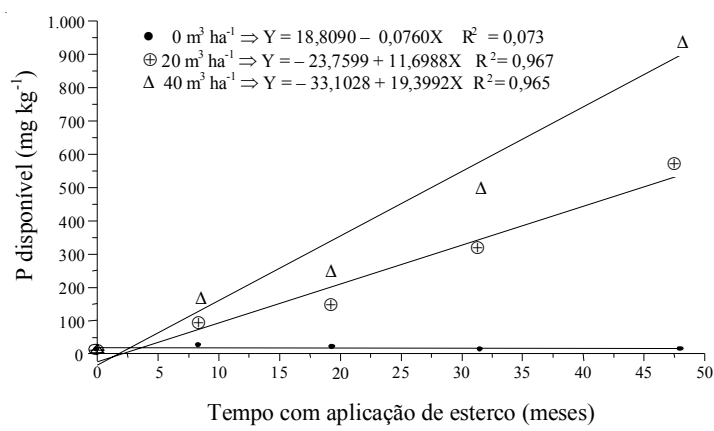

Figura 1. Fósforo disponível em solo com pastagem natural e com aplicação de doses de esterco líquido de suínos. (Média ponderada da camada 0-10 cm). respectivamente, com aplicação de $40 \mathrm{~m}^{3} \mathrm{ha}^{-1} \mathrm{em}$ relação aos $20 \mathrm{~m}^{3} \mathrm{ha}^{-1}$.

$\mathrm{O}$ teor de $\mathrm{K}$ disponível no solo diminuiu com a aplicação do esterco até a profundidade de $10-20 \mathrm{~cm}$. Até a profundidade de $5-10 \mathrm{~cm}$, a diminuição do teor de K no solo variou de $47 \%$ a $56 \%$ com a aplicação de $20 \mathrm{~m}^{3} \mathrm{ha}^{-1}$ e de $33 \%$ a $44 \%$, com o uso de $40 \mathrm{~m}^{3} \mathrm{ha}^{-1}$, demonstrando que a quantidade de $\mathrm{K}$ exportada na matéria seca da pastagem natural foi mais relevante quando se aplicou a menor dose de esterco. Em parte, isso pode ser justificado pela maior absorção relativa de K com a menor dose do esterco, cujos dados são mostrados por Durigon et al. (2002) que, neste mesmo experimento, determinaram que a quantidade absorvida de $\mathrm{K}$ pelas plantas em pastagem natural foi $45 \%$ e $32 \%$ do total aplicado nas doses de 20 e $40 \mathrm{~m}^{3} \mathrm{ha}^{-1}$, respectivamente. $\mathrm{O}$ fato de manter maiores teores de $\mathrm{K}$ disponível na área em que não foi aplicado esterco mostra que o tamponamento do solo é maior do que a quantidade exportada na matéria seca da pastagem.

O menor decréscimo no teor de $\mathrm{K}(25 \%$ a $28 \%)$ na profundidade de $20-40 \mathrm{~cm}$ pode ser considerado um indicativo da importância da sua exportação na matéria seca da pastagem natural, pois é acima desta profundidade do solo que se concentra a maior massa de raízes. Contudo, podem ocorrer perdas expressivas de $\mathrm{K}$ por escoamento superficial, pois a quase totalidade do $\mathrm{K}$ presente no esterco de suínos está na forma solúvel. Além disso, parte do K aplicado pode ter lixiviado além das camadas amostradas. Mesmo com 28 aplicações de $40 \mathrm{~m}^{3} \mathrm{ha}^{-1}$ de esterco, durante os quatro anos, o teor de $\mathrm{K}$ no solo ficou abaixo do nível crítico, que é de $80 \mathrm{mg} \mathrm{dm}^{-3}$ (Comissão de Fertilidade do Solo - RS/SC, 1995), a partir de $2,5 \mathrm{~cm}$ de profundidade.

A aplicação do esterco proporcionou aumento no teor de Ca trocável no solo até a camada $2,5-5,0 \mathrm{~cm}$. Na camada 0-2,5 cm, o aumento de Ca trocável foi de $50 \%$ e $49 \%$, enquanto na camada $2,5-5,0 \mathrm{~cm}$, o aumento foi de $36 \%$ e $40 \%$ nas doses de 20 e $40 \mathrm{~m}^{3} \mathrm{ha}^{-1}$, respectivamente. Esses porcentuais de acréscimo no teor de $\mathrm{Ca}$ no solo são relativamente pequenos, e podem ser justificados pela baixa concentração de Ca no esterco (Tabela 2), pela possibilidade de formação de compostos minerais com fosfatos ou, se- 
gundo Mendonça \& Rowell (1994), pela maior retenção de Ca pela matéria orgânica, diminuindo, desta maneira, sua extração pelo $\mathrm{KCl}$. Na matéria seca da pastagem natural, foi exportado $43 \%$ e $29 \%$ do $\mathrm{Ca}$ contido nas doses de 20 e $40 \mathrm{~m}^{3} \mathrm{ha}^{-1}$, respectivamente, determinado por Durigon et al. (2002).

Os teores de $\mathrm{Mg}$ aumentaram com a aplicação do esterco ao longo dos quatro anos (Figura 2) e foram dependentes das doses aplicadas, porque enquanto o acréscimo no teor de $\mathrm{Mg}$ nas camadas 2,5-5,0, 5-10 e $10-20 \mathrm{~cm}$ variou de $60 \%$ a $160 \%$ com a dose de $20 \mathrm{~m}^{3} \mathrm{ha}^{-1}$, os porcentuais elevaram-se para $207 \%$ a $323 \%$ com a aplicação de $40 \mathrm{~m}^{3} \mathrm{ha}^{-1}$, após os quatro anos (Tabela 3). À semelhança do que aconteceu com $\mathrm{K}$ e Ca, não houve efeito da aplicação do esterco no teor de $\mathrm{Mg}$ na profundidade de 20-40 cm de solo. Entretanto, quando se compara com as variações nos teores de $\mathrm{Ca}$, pode-se sugerir que uma das causas dos maiores incrementos de $\mathrm{Mg}$ no solo pode ser a maior capacidade de extração de $\mathrm{Mg}$ pelo $\mathrm{KCl} 1 \mathrm{~mol} \mathrm{~L}^{-1}$ usado na sua determinação.

O teor de Al trocável no solo diminuiu com a aplicação do esterco até a camada de 10-20 cm de profundidade e isso se refletiu no decréscimo da saturação de $\mathrm{Al}$ no solo, principalmente com o uso de $40 \mathrm{~m}^{3} \mathrm{ha}^{-1}$. Considerando-se que o Al é um dos principais fatores limitantes para o desenvolvimento das plantas em solos ácidos, é importante observar que os valores da saturação de Al onde não foi aplicado

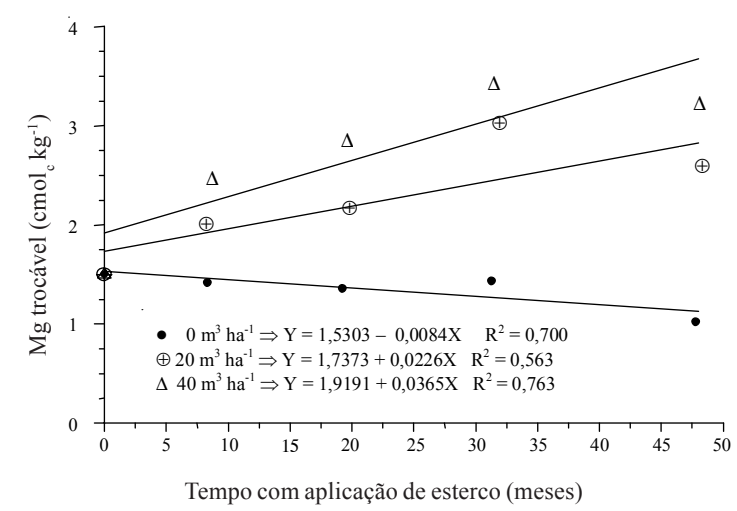

Figura 2. Magnésio trocável em solo com pastagem natural e sob aplicação de doses de esterco líquido de suínos. (Média ponderada da camada de 0-10 cm). esterco foram de $17,46,53,60$ e $78 \%$, ao passo que onde foi aplicado $20 \mathrm{~m}^{3} \mathrm{ha}^{-1}$, os valores foram de 1 , $18,42,51$ e $75 \%$ e na dose de $40 \mathrm{~m}^{3} \mathrm{ha}^{-1}$ os valores foram de 2, 10, 26, 46 e 70\%, nas profundidades de 0-2,5, 2,5-5, 0, 5,0-10, 10-20 e 20-40 cm, respectivamente. Contudo, abaixo de $5 \mathrm{~cm}$ de profundidade, os valores de saturação de $\mathrm{Al}$ se mantiveram altos, mesmo com a aplicação de esterco. Isso mostra que em muitos casos é possível obter maior eficiência no uso de esterco associando-se à prática da calagem.

A complexação de Al, especialmente pelas frações ácidos fúlvicos e húmicos da matéria orgânica, que são muito reativos e aumentam significativamente no solo com adições de altas quantidades de carbono (Ceretta, 1995), também pode justificar o grande decréscimo no teor de Al trocável até $5 \mathrm{~cm}$ de profundidade. Se por um lado não houve acréscimo no teor de $\mathrm{C}$ no solo, por outro lado, pode ter ocorrido alterações na qualidade da matéria orgânica, em virtude das características do $\mathrm{C}$ do esterco.

Apesar de ter sido detectada diferença significativa pelo teste de comparação de médias, pode-se, mais criteriosamente, considerar que o $\mathrm{pH}$ do solo praticamente não foi alterado com a aplicação do esterco.

\section{Conclusões}

1. O uso sistemático de esterco líquido de suínos representa a adição de grande quantidade de nutrientes ao solo, e eleva principalmente os teores de $\mathrm{P}$, $\mathrm{Ca}$ e $\mathrm{Mg}$ em áreas sob pastagem natural.

2. O ambiente para o crescimento das plantas pode ser melhorado com o uso de esterco líquido de suínos pela diminuição na saturação de alumínio.

3. A lixiviação de $\mathrm{N}$ e a elevada concentração de $\mathrm{P}$ na camada mais superficial do solo adubado com esterco líquido de suínos mostram que estes elementos podem comprometer a qualidade do ambiente, especialmente como contaminantes da água.

\section{Agradecimentos}

Aos produtores do Condomínio de suinocultores, ao eng. agrôn. Cezar Augusto Medeiros e ao técnico Agrícola José Valdetar da Silva Gomes, ambos da Emater/RS, ao eng. agrôn. Aldo Roberto 
Tisott (SLC Agrícola Ltda), aos alunos Jeferson Diekow e Naracelis Poletto (UFRGS), Paulo Sérgio Pavinato e Miguel Gustavo Herbes (UFSM), pela colaboração prestada na realização deste trabalho.

\section{Referências}

ALLISON, L. E. Organic carbon. In: BLACK, C. A. (Ed.). Methods of soil analysis, chemical and microbiological properties. Madison: American Society of Agronomy, 1965. pt. 2, p. 1367-1378. (Agronomy, 9).

BARCELLOS, L. A. R. Avaliação do potencial fertilizante do esterco líquido de bovinos. 1992. $108 \mathrm{f}$. Dissertação (Mestrado em Agronomia) - Universidade Federal de Santa Maria, Santa Maria, 1992.

BAYER, C.; MIELNICZUK, J. Dinâmica e função da matéria orgânica. In: SANTOS, G. A.; CAMARGO, F. A. O. (Ed.). Fundamentos da matéria orgânica do solo: ecossistemas tropicais e subtropicais. Porto Alegre: Genesis, 1999. p. 9-26.

CERETTA, C. A. Fracionamento de N orgânico, substâncias húmicas e caracterização de ácidos húmicos de solo em sistemas de cultura sob plantio direto. 1995. 127 f. Tese (Doutorado em Ciência do Solo) - Universidade Federal do Rio Grande do Sul, Porto Alegre, 1995.

COMISSÃO DE FERTILIDADE DO SOLO - RS/SC (Passo Fundo, RS). Recomendações de adubação e calagem para os Estados do Rio Grande do Sul e Santa Catarina. 3. ed. Passo Fundo: Sociedade Brasileira de Ciência do Solo/Embrapa, 1995. 224 p.

DURIGON, R.; CERETTA, C. A.; BASSO, C. J.; BARCELLOS, L. A. R.; PAVINATO, P. S. Produção de forragem em pastagem natural com o uso de esterco líquido de suínos. Revista Brasileira Ciência do Solo, Viçosa, MG, v. 26, p. 983-992, 2002.

EMBRAPA. Centro Nacional de Pesquisa do Solo (Rio de Janeiro, RJ). Sistema brasileiro de classificação de solos. Brasília: Embrapa SPI/Embrapa CNPS, 1999. 412 p.

GANGBAZO, G.; PESANT, A. R.; BARNETT, G. M.; CHARUEST, J. P.; CLUIS, D. Water contamination by ammonium nitrogen following the spreading of hog manure and mineral fertilizers. Journal of Environmental Quality, Madison, v. 24, p. 420-425, 1995.
GIUSQUIANI, P. L.; CONCEZZI, L.; BUSINELLI, M.; MACCHIONI, A. Fate of pig sludge liquid fraction in calcareous soil: agricultural and environmental implications. Journal of Environmental Quality, Madison, v. 27, p. 364-371, 1998.

HOUNTIN, J. A.; KARAM, A.; COUILLARD, D.; CESCAS, M. P. Use of a fractionation procedure to assess the potential for $\mathrm{P}$ movement in a soil profile after 14 years of liquid pig manure fertilization. Agriculture and Ecosystems Environment, Charlottetown, v. 78, p. 77 84, 2000.

MENDONÇA, E. S.; ROWELL, D. L. Dinâmica do alumínio e de diferentes frações orgânicas de um latossolo argiloso sob cerrado e soja. Revista Brasileira Ciência do Solo, Campinas, v. 18, p. 295-303, 1994.

MOAL, J. F.; MARTINEZ, J.; GUIZIOU, F.; COSTE, C. M. Ammonia volatilization following surface applied pig and cattle slurry in France. Journal of Agricultural Science, Cambridge, Inglaterra, v. 125, p. 245-252, 1995.

N'DAYEGAMIYE, A.; CÔTÉ, D. Effect of long term pig slurry and solid cattle manure application on soil chemical and biological properties. Canadian Journal of Soil Science, Ottawa, v. 69, p. 39-47, 1989.

PRATT, P. F. Management restrictions in soil application of manure. Journal of Animal Science, Washington, v. 48, p. $134-143,1979$.

REDOY, K. R.; KHALEEL, R.; OVERCASH, M. R.; WESTERMAN, P. W. A moinpoint source model for land areas receiving animal wastes $-\mathrm{I}$ : mineralization of organic nitrogen. Transaction of the American Society of Agricultural Engineers, Michigan, v. 22, p. 863-872, 1979.

SCHERER, E. E.; CASTILHOS, E. G.; JUCKSCH, I.; NADAL, R. Efeito da adubação com esterco de suínos, nitrogênio e fósforo em milho. Florianópolis: Empasc, 1984. 26 p. (Boletim Técnico, 24).

SHARPLEY, A. N.; REKOLAINEN, S. Phosphorus in agriculture and its environmental implications. In: TUNNEY, H.; SMYTH, T. J.; TIESSEN, H. Phosphorus loss from soil to water. Wallingford: $\mathrm{CAB}, 1997$. p. 1-54.

TEDESCO, M. J.; GIANELLO, C.; BISSANI, C. A.; BOHNEN, H.; VOLKWEISS, S. J. Análises de solo, plantas e outros materiais. 2. ed. Porto Alegre: UFRGS, 1995. $174 \mathrm{p}$. 